\title{
EFEK SAMPING PEMAKAIAN KB SUNTIK 3 BULAN PADA AKSEPTOR DI BIDAN PRAKTIK SWASTA (BPS) HJ. NORHIDAYATI BANJARMASIN
}

\author{
Dian Purnama Sari \\ Akademi Kebidanan Bunga Kalimantan, Banjarmasin, Kalimantan Selatan, Indonesia, 70123 \\ Email : dian.purnamasari88@yahoo.com
}

\begin{abstract}
The side effects of using three-month injectable contraceptives have become an interesting discussion among acceptors and health workers. A preliminary survey conducted by researchers at the Private Practice Midwife (BPS) Mrs. Hj. Norhidayati in April 2021 showed that there were 150 active family planning acceptors with a total of 60 acceptors for 3-month injections (Medroxyprogesterone acetate). The results of interviews conducted by researchers with 10 acceptors of 3-month injections showed that mothers experienced side effects of 3-month injections, one person experienced dizziness (10\%), menstrual pattern was disturbed (amenorrhoea) 4 people (40\%), bleeding (spotting) 2 people (20\%) and as many as 3 people (30\%) experienced weight gain. This study was a descriptive study to describe the side effects of the use of family planning. The population used in this study were acceptors who used 3-month injectable contraception at BPS Hj. Norhidayati Banjarmasin, from March - April 2021 with a total population of 60 acceptors. The sample that became the research subject was 60 people who used injectable contraception for 3 months. The sampling technique used was total sampling. The results showed that the number of family planning acceptors who used 3-month injections showed that the side effects of using 3-month injectable contraceptives were menstrual pattern disorders 47 (78\%), bleeding 29 people (48\%), weight gain 36 (60\%), pain disorders 22 people (37\%), who experienced bloating, pain 20 people (33\%) and who experienced high blood pressure as many as 31 people (52\%). The side effects of using 3-month injectable contraceptives are still and will be felt by 3 months of family planning acceptors. Health workers, especially midwives, are expected to be able to provide information or health education regarding these side effects to users of injectable family planning at BPS or other health care facilities.
\end{abstract}

Keyword: Acceptors for 3-month injections, Private Practice Midwife

\begin{abstract}
Abstrak
Efek samping penggunaan KB suntik tiga bulan sudah menjadi perbincangan yang menarik dikalangan akseptor dan para petugas kesehatan. Survey pendahuluan yang dilakukan oleh peneliti pada Bidan Praktik Swasta (BPS) Ibu Hj. Norhidayati pada April 2021 mennjukkan jumlah akseptor KB aktif sebanyak 150 orang dengan jumlah akseptor suntik 3 bulan (Depo Medroksi Progesteron Asetat) sebanyak 60 akseptor. Hasil wawancara yang dilakukan peneliti dengan 10 akseptor suntik 3 bulan menunjukkan bahwa ibu mengalami efek samping suntik 3 bulan, 1 orang mengalami pusing (10\%), pola haid terganggu (amenorea) 4 orang (40\%), perdarahan ( bercak) 2 orang $(20 \%)$ dan sebanyak 3 orang $(30 \%)$ mengalami peningkatan berat badan. Penelitian ini merupakan penelitian deskriptif untuk menggambarkan efek samping dari penggunaan KB. Populasi yang digunakan dalam penelitian ini adalah akseptor yang menggunakan kontrasepsi suntik 3 bulan di BPS Hj. Norhidayati Banjarmasin, dari bulan Maret - April 2021 dengan jumlah populasi 60 akseptor. Sampel yang menjadi subjek penelitian sebanyak 60 orang yang menggunakan KB suntik selama 3 bulan. Teknik pengambilan sampel yang digunakan adalah total sampling. Hasil penelitian menunjukkan bahwa jumlah akseptor KB yang menggunakan suntik 3 bulan menunjukkan efek samping penggunaan kontrasepsi suntik 3 bulan adalah gangguan pola menstruasi 47 orang $(78 \%)$, perdarahan 29 orang (48\%), penambahan berat badan $36(60 \%)$, gangguan sakit kepala 22 orang (37\%), yang mengalami perut kembung, nyeri 20 orang (33\%) dan yang mengalami tekanan darah tinggi sebanyak 31 orang (52\%). Efek samping penggunaan KB suntik 3 bulan masih dan akan dirasakan oleh akseptor KB 3 bulan. Petugas kesehatan, teruatama bidan diharapkan dapat memberikan informasi atau pendidikan kesehatan mengenai efek samping ini kepada pengguna KB suntik di BPS atau fasilitas pelayanan kesehatan lainnya.
\end{abstract}

Kata kunci: Akseptor KB suntik, bidan praktik swasta 


\section{Pendahuluan}

Metode kontrasepsi suntikan merupakan salah satu metode keluarga berencana yang popular dan menjadi gerakan keluarga berencana nasional serta peminatnya dari tahun ke tahun semakin bertambah (Prawirohardjo, 2005). Selain karena metode kontrasepsi suntikan dapat membantu mengurangi masalah-masalah kewanitaan yang paling dasar dan utama bagi kesehatan reproduksi, pemakaian suntikan KB aman, sederhana dan efektif, namun akseptor harus menggunakan suntikan $\mathrm{KB}$ secara periodik atau setiap 3 bulan sekali harus melakukan kunjungan ke pelayanan kesehatan baik bidan, puskesmas ataupun ke dokter.

Kontrasepsi suntik 3 bulan tidak menimbulkan gangguan namun tetap mempunyai kekurangan dan efek samping. Seorang akseptor KB suntik 3 bulan beberapa waktu setelah penggunaan kontrasepsi tersebut terkadang mengalami beberapa gangguan seperti sakit kepala, gangguan haid dan peningkatan atau penurunan berat badan. Efek samping ini dapat segera hilang dengan dilakukan pengobatan ataupun tidak dilakukan pengobatan. Akseptor yang tidak siap menghadapi perubahan ataupun gejala yang ditimbulkan oleh penggunaan konstrasepsi suntik 3 bulan seringkali menimbulkan kecemasan pada diri akseptor. Kecemasan yang terjadi pada diri akseptor $\mathrm{KB}$ suntik 3 bulan dapat menjadikan akseptor tersebut beralih menggunakan metode kontrasepsi lainnya. Hal ini dikarenakan sebagian besar pengguna metode kontrasepsi suntik 3 bulan tidak mengetahui tentang efek samping penggunaan metode kontrasepsi suntik 3 bulan (Mirudin, 2008). Untuk itu seorang akseptor sebelum memilih alat kontrasepsi, harus mengetahui tentang metode kontrasepsi yang akan dipilihnya baik meliputi cara pemasangan atau penggunaannya, efek yang mungkin ditimbulkan dan berbagai informasi seputar metode kontrasepsi yang dipilihnya.

Metode kontrasepsi yang paling banyak digunakan di seluruh dunia adalah sterilisasi. Metode kontrasepsi hormon berada pada posisi ketiga di seluruh dunia. Data orang yang menggunakan pil sebanyak 85\%, sedangkan kontrasepsi implant dan suntik hanya $15 \%$ (Glasier, 2005). Kekurangan dari kontrasepsi suntik adalah terganggunya pola haid diantaranya amenorrheo, moenoragia, dan muncul bercak (spotting), terlambatnya, peningkatan berat badan (Saifuddin, 2011).

Pada negara maju metode kontrasepsi yang paling populer adalah kontrasepsi oral (16\%). Sebaliknya di negara-negara sedang berkembang sterilisasi wanita $(20 \%)$, AKDR (13\%), kontrasepsi oral (6\%) dan vasektomi (5\%) (Glasier, 2005). Indonesia, pada tahun 2012 tercatat jumlah peserta KB aktif dari
64.133.347 juta jiwa, dengan jumlah PUS 161.750.743 juta jiwa dan Wanita usia subur (WUS) 51.472.069 juta jiwa (Kemenkes RI, 2010). Dari 64.133.347 peserta Keluarga berencana (KB) aktif, pengguna KB suntik $(54,35 \%)$, peserta pil $(28,65 \%)$, peserta Intrauterine device (IUD) (5,44\%), peserta kondom $(5,34 \%)$, peserta implant $(4,99 \%)$, peserta Metode Operasi Wanita (MOW) $(1,04 \%)$, dan peserta Metode Operasi Pria (MOP) (0,2\%). (Hendra, 2017).

Hasil survei pendahuluan yang peneliti peroleh di BPS ibu Hj. Norhidayati bulan April 2021 jumlah akseptor KB aktif 150 akseptor, dengan jumlah akseptor KB suntik 3 bulan (Depo Medroksi Progesterone Acetat) sebanyak 60 akseptor . Hasil wawancara yang dilakukan peneliti terhadap 10 orang akseptor KB suntik 3 bulan, ibu mengalami efek samping KB suntik 3 bulan mengalami pusing 1 orang (10\%), terganggu pola haid (amenorrheo) sebanyak 4 orang (40\%), perdarahan (spotting) 2 orang (20\%) dan sebanyak 3 orang (30\%) mengalami peningkaan berat badan.

Berdasarkan uraian diatas peneliti tertarik untuk meneliti tentang Efek Samping Pemakaian KB Suntik 3 Bulan pada Akseptor di BPS $\mathrm{Hj}$. Norhidayati Banjarmasin Tahun 2021.

\section{Metode Penelitian}

Penelitian ini merupakan penelitian deskriptif yaitu suatu penelitian untuk mendiskripsikan suatu keadaan yaitu ingin mengambarkan efek samping pemakaian $\mathrm{KB}$ dengan menggunakan kuisioner untuk mengukur efek samping penggunaan KB Suntik 3 bulan yaitu, gangguan haid, perdarahan, kenaikan berat badan, sakit kepala, nyeri dan tekanan darah tinggi.

Populasi yang digunakan dalam penelitian ini adalah akseptor yang menggunakan KB suntik 3 bulan di BPS Hj. Norhidayati Banjarmasin, dari bulan MaretApril 2021 dengan jumlah populasinya 60 akseptor. Sampel yang menjadi subyek penelitian adalah akseptor $\mathrm{KB}$ yang memakai KB suntik 3 bulan berjumlah 60 orang. Teknik sampling yang digunakan adalah total Sampling.

Variabel dalam penelitian ini adalah efek samping pemakaian KB suntik 3 bulan. Data yang diperoleh selanjutnya dianalisis dengan menggunakan statistik deskriptif dan ditampilkan dengan menggunakan tabel distribusi frekuensi. 


\section{Hasil Penelitian}

Responden dalam penelitian ini adalah akseptor KB suntik 3 bulan di BPS $\mathrm{Hj}$. Norhidayati jumlah responden yang memenuhi kriteria inklusi ada 60 orang.

Tabel 1. Distribusi Frekuensi Akseptor KB Suntik 3 Bulan yang mengalami Gangguan Haid di BPS $\mathrm{Hj}$. Norhidayati

\begin{tabular}{llcl}
\hline No & Gangguan Haid & Jumlah & \% \\
\hline 1 & Tergangu & 47 & 78 \\
2 & Tidak terganggu & 13 & 22 \\
& Jumlah & 60 & 100 \\
\hline
\end{tabular}

Sumber: Data Primer 2021

Tabel 1 di atas menunjukkan bahwa akseptor KB yang menggunakan suntik KB 3 bulan yang mengalami gangguan haid berjumlah 47 orang (78\%) dan tidak terganggu 13 orang (22\%).

Tabel 2. Distribusi Frekuensi Aksepor KB Suntik 3 Bulan yang mengalami Perdarahan di Norhidayati

\begin{tabular}{lllll}
\hline No. & $\begin{array}{l}\text { Mengalami } \\
\text { Perdarahan }\end{array}$ & Jumlah & & $\%$ \\
\hline 1. & Perdarahan & 29 & 48 & \\
2. & Tidak perdarahan & 31 & 52 & \\
\hline & Jumlah & 60 & 100 \\
\hline
\end{tabular}
Sumber :Data Primer 2021

Tabel 2 menunjukkan akseptor KB suntik 3 bulan yang mengalami Perdarahan 29 orang (48\%) dan tidak terganggu 31 orang $(52 \%)$.

Tabel 3. Distribusi Akseptor KB Suntik 3 Bulan yang mengalami Kenaikan Berat Badan di BPS Hj. Norhidayati.

\begin{tabular}{|c|c|c|c|}
\hline No. & $\begin{array}{l}\text { Kenaikan Berat } \\
\text { Badan }\end{array}$ & Jumlah & $\%$ \\
\hline 1. & Naik berat badan & 36 & 60 \\
\hline \multirow[t]{2}{*}{2.} & $\begin{array}{l}\text { Tidak Naik berat } \\
\text { badan }\end{array}$ & 24 & 40 \\
\hline & Jumlah & 60 & 100 \\
\hline
\end{tabular}

Tabel 3 menunjukkan akseptor KB suntik 3 bulan yang mengalami kenaikan berat badan ada 36 orang $(60 \%)$ dan tidak mengalami kenaikan berat badan ada 24 orang $(40 \%)$.

Tabel 4. Distribusi Frekuensi Akseptor KB Suntik 3 Bulan yang mengalami Sakit Kepala di BPS Hj. Norhidayati.

\begin{tabular}{|c|c|c|c|}
\hline No. & $\begin{array}{l}\text { Mengalami } \\
\text { sakit Kepala }\end{array}$ & Jumlah & $\%$ \\
\hline 1. & Sakit Kepala & 22 & 36 \\
\hline 2. & $\begin{array}{ll}\text { Tidak } & \text { sakit } \\
\text { Kepala } & \\
\end{array}$ & 38 & 63 \\
\hline & Jumlah & 60 & 100 \\
\hline
\end{tabular}

Tabel 4 menunjukkan akseptor KB suntik 3 bulan yang mengalami sakit kepala ada 22 orang (37\%) dan tidak mengalami efeksamping sakit kepala ada $38(63 \%)$.

Tabel 5. Distribusi Frekuensi Akseptor KB Suntik 3 Bulan yang mengalami Nyeri di BPS Hj. Norhidayati

\begin{tabular}{llll}
\hline No. & $\begin{array}{l}\text { Mengalami } \\
\text { Nyeri }\end{array}$ & Jumlah & \% \\
\hline 1. & Nyeri & 20 & 34 \\
2. & Tidak Nyeri & 40 & 66 \\
\hline & Jumlah & 60 & 100 \\
\hline
\end{tabular}

Sumber:Data Primer 2021

Tabel 5 menunjukkan akseptor KB suntik 3 bulan yang mengalami Nyeri ada 20 orang (34\%) sedangkan yang tidak mengalami nyeri ada 40 orang $(66 \%)$.

Tabel 6. Distribusi Frekuensi Akseptor KB Suntik 3 Bulan yang mengalami Tekanan Darah Tinggi di BPS Hj. Norhidayati

\begin{tabular}{llcl}
\hline No. & $\begin{array}{l}\text { Mengalami } \\
\text { Tekanan } \\
\text { Darah } \\
\text { Tinggi }\end{array}$ & Jumlah & \% \\
\hline 1. & Naik & 31 & 52 \\
2. & Tidak & 29 & 48 \\
\hline & Jumlah & 60 & 100
\end{tabular}

Sumber:Data Primer 2021

Tabel 6 di atas menunjukkan akseptor KB suntik 3 bulan yang mengalami tekanan darah tinggi ada 31 orang (52\%) sedangkan yang tidak sakit kepala ada 29 orang $(48 \%)$.

\section{Pembahasan}

Penelitian ini menunjukkan bahwa akseptor $\mathrm{KB}$ suntik 3 bulan yang mengalami gangguan haid adalah sebanyak $78 \%$. Penemuan ini sejalan dengan pendapat Suratun (2008) yang menyatakan bahwa progesteron yang terkandung dalam KB suntik, kadang tidak sesuai dengan kondisi dinding uterus (endometrium). Gangguan pola haid menorragia disebabkan karena ketidakseimbangan hormon estrogen dan progesteron sehingga menimbulkan endometrium menghasilkan volume yang lebih banyak.

Penelitian ini menunjukkan bahwa akseptor $\mathrm{KB}$ suntik 3 bulan menggalami gangguan perdarahan atau spotting sebanyak $48 \%$. Hal ini sejalan dengan pernyataan Hartanto (2005) yang menyatakan bahwa perdarahan atau spotting terjadi karena menurunnya hormon estrogen dan kelainan atau 
terjadinya gangguan hormon. Hal ini sering terjadi pada penggunaalat kontrasepsi, terutama KB Suntik. Penelitian ini menunjukkan bahwa akseptor KB suntik tiga bulan mengalami kenaikan berat badan sebanyak $60 \%$. Hal ini sejalan dengan pernyataan dari Hartanto (2008) yang menyatakan bahwa kenaikan berat badan disebabkan karena hormon progesteron mempermudah perubahan karbohidrat dan gula menjadi lemak, sehingga lemak di bawah kulit bertambah. Selain itu, hormon progesteron yang terdapat dan ditemukan di KB suntik juga menyebabkan nafsu makan bertambah dan menurunkan aktivitas fisik, akibatnya pemakaian suntikan $\mathrm{KB}$ dapat menyebabkan berat badan bertambah.

Penelitian ini menunjukkan bahwa akseptor $\mathrm{KB}$ suntik 3 bulan mengalami sakit kepala sebanyak $37 \%$. Penemuan ini sejalan dengan penyataan dari Suratun (2008) ang menyatakan bahwa sakit kepala pada pemakaian KB Suntik 3 bulan, dapat disebabkan karena reaksi tubuh terhadap progestreon sehingga hormon estrogen fluktuatif (mengalami penekanan) dan progesteron dapat mengikat air sehingga sel-sel di dalam tubuh mengalami perubahan sehingga terjadi penekanan pada syaraf otak.

Penelitian ini menunjukkkan bahwa akseptor $\mathrm{KB}$ suntik 3 bulan mengalami nyeri sebanyak $33 \%$. Penemuan ini sesuai dengan pendapat dari Varney (2007) yang menyatakan bahwa pengguna kontrasepsi suntik 3 bulan yang mengalami nyeri, kemungkinan disebabkan oleh penyakit bawaan yang pernah akseptor derita seperti, kram. Seorang wanita yang mulai menggunakan Depo Provera harus mendapat saran tentang kemungkinan sakit pada badan, nyeri, kram.

Penelitian ini menunjukkan bahwa akseptor KB suntik 3 bulan mengalami tekanan darah tinggi sebanyak 52\%. Penemuan ini sesuai dengan teori Suratun (2008) dan Vaney (2007) yang menyatakan bahwa kandungan dalam KB suntik dapat menyebabkan reaksi tubuh terhadap progestreon sehingga hormon estrogen fluktuatif (mengalami penekanan) dan progesteron dapat mengikat air sehingga sel di dalam tubuh mengalami perubahan sehingga terjadi penekanan pada syaraf otak. Sakit kepala yang dirasakan oleh pengguna kontrasepsi suntik 3 bulan kemungkinan disebabkan oleh penyakit bawaan yang pernah akseptor derita seperti migren. Seorang wanita yang mulai menggunakan Depo Provera harus mendapat saran tentang kemungkinan sakit kepala.

\section{Kesimpulan}

Hasil penelitian ini menunjukkan bahwa jumlah akseptor KB yang menggunakan KB suntik 3 bulan adalah sebanyak 60 orang. Efek samping yang muncul dari pemakaian KB suntik 3 bulan berupa terganggunya pola haid berjumlah 47 orang $(78 \%)$, perdarahan berjumlah 29 orang $(48 \%)$, kenaikan berat badan berjumlah $36(60 \%)$, gangguan sakit kepala berjumlah 22 orang $(37 \%)$, nyeri perut 20 orang $(33 \%)$ dan yang mengalami tekanan darah tinggi sebanyak 31 orang (52\%).

Bidan Praktik Swasta (BPS) sebaiknya dapat lebih meningkatkan penyuluhan kesehatan pada masyarakat/akseptor tentang KB Suntik 3 Bulan sehingga pengetahuan akseptor KB lebih baik. Bagi Akseptor yang sudah mengalami efek samping sebaiknya di anjurkan ke puskesmas. Bagi peneliti selanjutnya diharapkan dapat meneliti variabel lainnya. Bagi Institusi Pendidikan sebaiknya dapat menambah referensi pengajaran mengenai efek samping KB suntik 3 bulan.

\section{Acknowledgement}

Ucapan terima kasih kapada responden dan Bidan BPS yang telah bersedia membantu peneliti dalam proses penelitian sehingga bisa didapatkan hasil yang dapat bermanfaat bagi responden khususnya ibu dengan akseptor $\mathrm{KB}$ dan pemilihan $\mathrm{KB}$ secara baik.

\section{Daftar Pustaka}

Arikunto,S. 2002. prosedur Penelitian Edisi Revisi V. jakarta : Rine Cipta

$$
\text { 2006. prosedur Penelitian Edisi }
$$

Revisi $V$. jakarta : Rine Cipta.

BKKBN. 2004. Kontrasepsi suntik.Jakarta. (online). Availabe: (http://www.bkkbn.go.Com//id, di akses pada tanggal 11 maret 2021.

Dinkes. 2009 .Definisi Akseptor KB.

Availableonline:

http://www.dinkes.com.tanggalakses akses 11 Maret 2021

Everett, S. 2008. Buku Saku Kontrasepsi dan Kesehatan seksual Refruduktif. Jakarta : EGC Handayani,S.2010. Pelayanan Keluarga Berencana. Yogyakarta: Pustaka Rihana.

Harnawatiajh. 2009.KB suntik.available online; http://www.BukuKB.google.com, diakses tanggal 20 februari 2021.

Hartanto,H. 2004. Keluwarga Berencana dan Kontrasepsi. Jakarta: Pustaka Sinar Harapan. 2003. Keluwarga Berencana dan Kontrasepsi. Jakarta: Pustaka Sinar Harapan. Hidayat,A.A.A 2009.Metode Penelitian Kebidanan dan Teknis Analisis Data. 2010. Metode Penelitian Kebidanan dan Teknis Analisis Data. Jakarta ; Salemba Medika.

Kadilaju, Karangnonko, Klaten. KTI.DIII Kebidanan. Poltekes Surakarta. Jakarta: EGC. Kristiyani,A.2006. faktor-faktor yang Berhubungan dengan Akseptor KB Memilih 
Jurnal Keperawatan Suaka Insan (JKSI) Vol. 6, No. 2, Desember 2021

Kontrasepsi Suntik di Puskesmas Pembantu tanggal akses 18 februari 2021.

Saifudin, A. B. 2006. Buku Panduan

Praktis Pelayanan Kontrasepsi. Jakarta: Yayasan Bina Pustaka.
Soekanto,S.2003. Buku Panduan Praktis Pelayanan Kontrasepsi. Jakarta : Yayasan Bina Pustaka Sarwono Prawirodiharjo.

Suratun,dkk.2008. Pelayanan Keluwarga Berencana \& Pelayanan Kontrasepsi. Jakarta :Trans Info Media. 